\title{
Sustainable Management of Spent Hydroprocessing Catalyst
}

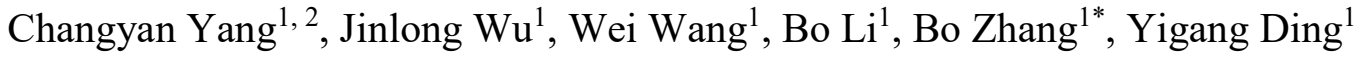 \\ 1: Key Laboratory for Green Chemical Process of Ministry of Education, Hubei Key Laboratory of Novel \\ Chemical Reactor and Green Chemical Technology, School of Chemical Engineering and Pharmacy, \\ Wuhan Institute of Technology, Hubei, China \\ 2: Hubei Key Laboratory for Processing and Application of Catalytic Materials, Huanggang Normal \\ University, Hubei, China
}

Received February 6, 2018; Accepted May 2, 2018; Published May 3, 2018

\begin{abstract}
Increasing demand for high-quality transportation fuels and stringent environmental standards have resulted in the significantly increased quantity of spent hydroprocessing catalysts, which require the sustainable management. To minimize the generation of hazardous wastes, the spent hydroprocessing catalysts can be regenerated via oxidative regeneration or reactivated via the rejuvenation process. If the catalytic activity cannot be restored, it can be utilized as a source of other useful materials, and/or metals in the spent catalyst are recovered. Finally, the stabilized residues shall be disposed by using an environmentally sound method.
\end{abstract}

Keywords: Sustainable Management; Spent Hydroprocessing Catalyst; Oxidative Regeneration; Rejuvenation; Metals Reclamation

\section{Introduction}

Increasing demand for high-quality transportation fuels and stringent environmental standards have resulted in the significant growth of the use of hydroprocessing catalysts globally. It is expected that the amount of spent hydroprocessing catalysts produced will be 200,000 tons annually with an anticipated 5\% annual increase [1]. Therefore, the sustainable management of these spent catalyst wastes will reduce the pollution to the environment and increase the economic efficiency of the hydrogenation process.

Hydroprocessing catalysts generally include hydrotreating and hydrocracking catalysts. The most used hydrotreating catalysts are molybdate (Mo) supported on alumina $\left(\mathrm{Al}_{2} \mathrm{O}_{3}\right)$ and promoted by cobalt $(\mathrm{Co})$, nickel $(\mathrm{Ni})$ or tungsten $(\mathrm{W})$, while hydrocracking catalysts are bifunctional, and consisting of active metals (like Mo, Pt, and $\mathrm{Ru}$ ) supported on a zeolite (e.g., ZSM-5). The catalyst life varies for different applications: 1-2 years for hydroprocessing of atmospheric gas oils or vacuum gas oils, 0.5-1 year for hydrotreating resid, 5-10 years for a naphtha hydrotreater using straight run feed [2], and $\sim 2$ years for hydrotreating bio-feedstock [3, 4].

When the performance of the catalysts cannot meet the desired level, they will be unloaded and examined for its regenerateness. After regeneration, the regenerated spent hydroprocessing catalysts will be re-evaluated. Catalysts of a good quality are pooled and re-sulfided for reusing, while catalysts with a lower quality could be reused in less critical 
applications. For the spent catalyst has lost its regenerateness, the metal in the spent catalyst will be recycled to the maximum extent. The residues are disposed by using an environmentally sound method.

\section{Oxidative Regeneration}

Oxidative regeneration is mainly used to burn off the coke deposited on the spent hydrotreating catalysts and transform metal sulfides back into their oxides. But it could not recover the structural properties to the same level as the fresh catalysts. Typically, the spent catalyst should not contain more than $2-3 \mathrm{wt} \%$ of metal contaminants (mostly $\mathrm{Ni}$ and $\mathrm{V}$ ) to be suitable for oxidative regeneration [5].

This regeneration process is affected by multiple factors including $\mathrm{O}_{2}$ supply, the composition of the coke, and mass transfer. Air generally provides a good $\mathrm{O}_{2}$ source. However, the uncontrolled temperature increase may lead to sintering of the catalyst. Under certain circumstances, diluted air may be more suitable.

The temperature is the most critical factor. It is found that a complete removal requires burning at the high temperature of $\sim 450^{\circ} \mathrm{C}$, if burning the sulfided spent CoMo catalysts [6]. Oxidation of sulfidic sulfur and organic sulfur resulted in the release of $\mathrm{SO}_{2}$ at $250^{\circ} \mathrm{C}$ and $450^{\circ} \mathrm{C}$, respectively. Oxidation of carbon also happens at $\sim 450^{\circ} \mathrm{C} \mathrm{[7].} \mathrm{More}$ severe oxidation conditions are needed for the $\mathrm{NiW}$ catalyst, because of the lower oxidation activity of $\mathrm{NiO}$ and $\mathrm{WO}_{3}$ compared to $\mathrm{Co}_{3} \mathrm{O}_{4}$ and $\mathrm{MoO}_{3}$ [8]. The removal of sulfidic sulfur from the spent $\mathrm{NiW}$ catalysts as $\mathrm{SO}_{2}$ happened at $227-327^{\circ} \mathrm{C}$ and the removal of carbon as $\mathrm{CO}_{2}$ or $\mathrm{CO}$ occurred at $377-577^{\circ} \mathrm{C}$.

The shapes of the catalysts establish the mass transfer limitations, which may be minimized by grinding the deactivated catalyst to a fine particle size $[9,10]$.

The oxidative regeneration can be carried out in situ or ex situ. The conventional in-situ technique burns off the coke and re-sulfides the catalyst in the hydrotreating reactors. Regeneration is performed by injecting a stream of diluted air with nitrogen or steam to remove coke and reversible poisons like sulfur and nitrogen by oxidizing them at temperatures between $450-550^{\circ} \mathrm{C}$ into gaseous $\mathrm{CO}, \mathrm{CO}_{2}, \mathrm{SO}_{\mathrm{x}}$, and $\mathrm{NO}_{\mathrm{x}}$. The process parameters such as air concentration and temperature are carefully controlled to prevent runaway combustion [11]. Following regeneration, sulfiding converts the metal oxides impregnated onto the catalyst support into the corresponding metal sulfides, and forms $\mathrm{H}_{2} \mathrm{~S}$ that can enter the process water to be removed. According to environmental regulations, acidic gases must be neutralized, and the neutralization process is timeconsuming and requires injection systems, trained operators, and time. Forth more, in-situ regeneration requires long unit downtime and gives poor activity recovery due to uneven gas flow [12].

The ex situ (also called off-site) oxidative regeneration has been widely accepted by the petroleum refining industry in the $1990 \mathrm{~s}$, because it provides benefits on safety, time savings, and less environmental problems caused by generating $\mathrm{SO}_{\mathrm{x}}$ and $\mathrm{CO}_{\mathrm{x}}$. Better activity recovery can be achieved by the ex situ regeneration, because it allows performing more than one cycle with the same catalyst batch [13]. The reactor corrosion due to the formation of acidic gases is eliminated. The chance for accidents, hot spots, and reactor malfunction is lower. Dedicated catalyst specific regeneration procedures can be applied, and the fines can be removed by screening. The costs of the oxidative ex situ regeneration are around $20 \%$ of the fresh catalyst price [14]. 


\section{Rejuvenation}

The rejuvenation of spent catalysts, also known as reactivation or reactivation, is additional processes that may be required. Oxidative regeneration is typically performed on older generation Type I catalysts, with recovered activity in the range of $70-85 \%$ of fresh activity, depending on the degree of metals contamination and surface area. For more recent generation catalysts containing the highly active Type II sites, the oxidative regeneration of Type II catalysts only results in a mediocre activity recovery. One possible reason for this low-activity recovery is that these catalysts have not been exposed to the temperatures that are required to restore their activities. The rejuvenation process developed by Porocel [15] consists of two steps: an initial thermal regeneration to remove the carbon and sulfur, followed by a proprietary chemical treatment to remove the inactive crystalline compound such as $\beta-\mathrm{CoMoO}_{4}$ or $\mathrm{NiMoO}_{4}$, re-disperse the metals, and restore the Type II active sites for maximum activity recovery. These treatments typically use some oxygen containing compounds that play the role of chelating agents and thus may help re-disperse the metals [16]. Rejuvenation of the spent catalyst may restore greater than $90 \%$ of fresh catalyst activity and provide the spent catalysts that meet certain physical and chemical criteria.

\section{Reuse of the Spent Catalysts}

Reuse of a regenerated spent catalyst to maximize the catalyst life is the key to the sustainable management. The regenerated catalysts may be suitable for less demanding refinery operations. Typically, the regenerated gas oil hydrotreating catalyst might be used for hydrotreating of kerosene, and the regenerated Kerosene hydrotreating catalyst can be applied for naphtha hydrotreating [17].

It's also possible to use at least a small portion of spent catalysts for the preparation of useful materials like fused alumina, Anorthite glass-ceramics, and abrasive material [18]. Depending on the remaining porosity and surface area, spent catalysts may still have potential especially, in some gas-solid applications, e.g., used as a $\mathrm{H}_{2} \mathrm{~S}$ clean-up sorbent [19].

This kind of catalyst management services could provide sustainability to the global catalyst inventory through a pool where each site or unit will take the required catalyst quantity corresponding to their need.

\section{Metals Reclamation}

When the spent catalyst reaches the end-of-cycle, i.e., the desired level of activity could not be restored, or the mechanical properties would strongly deteriorate during regeneration. Metals reclamation could remove toxic components and make further dispose of residues possible [20].

There are two types of reclamation processes: hydrometallurgy and pyrometallurgy. The hydrometallurgical reclamation involves the solubilization of metals via roasting, followed by a selective leaching of metals of interest [21]. Literature 
regarding the hydrometallurgical reclamation of metals is extensive, and has been reviewed by Furimsky [21] and Marafi and Stanislaus [18, 22].

The pyrometallurgical process starts with melting dry catalysts in a furnace at temperatures around $1200-1500^{\circ} \mathrm{C}$ [23]. Heavy metals sink to the bottom as alloys containing the alumina or silica support, which are further separated from the slag. Pyrometallurgical processes for recovering metals (like Pt and Pd) in hydrocracking catalysts involve chlorination at high temperatures $\left(900-950^{\circ} \mathrm{C}\right)$ for recovery of platinum and other metals as volatile chlorides, which is followed by heating at high temperatures $\left(800^{\circ} \mathrm{C}\right)$ in a gas flow containing water [24].

\section{CONCLUSIONS}

As the energy demand continues to rise and the environmental regulations are more stringent, the increasing quantity of spent hydroprocessing catalysts requires the sustainable management, which has a goal of minimizing the generation of hazardous wastes. The spent hydroprocessing catalysts can be regenerated via oxidative regeneration and re-sulfided or reactivated via the rejuvenation process, if it meets the requirements of the regenerateness. If the catalytic activity cannot be restored, it can be utilized to make other useful materials, and/or metals in the spent catalyst are recovered. Finally, the stabilized residues of spent hydroprocessing catalysts can be disposed in landfills.

\section{ACKNOWLEDGMENTS}

We are grateful for the support from the School of Chemical Engineering and Pharmacy at the Wuhan Institute of Technology.

\section{CONFLICTS OF INTEREST}

The authors declare that there is no conflict of interests regarding the publication of this paper.

\section{REFERENCES}

[1] Chiranjeevi, T., Pragya, R., Gupta, S., Gokak, D. T., and Bhargava, S. (2016). Minimization of Waste Spent Catalyst in Refineries. Procedia Environmental Sciences, 35, 610-617.

[2] Dufresne, P. (2007). Hydroprocessing catalysts regeneration and recycling. Applied Catalysis A: General, 322, 67-75.

[3] Zhang, B., and Seddon, D. (2018). Hydroprocessing Catalysts and Processes: The Challenges for Biofuels Production, World Scientific Publishing, Singapore.

[4] Zhang, B., and Wang, Y. (2013). Biomass Processing, Conversion, and Biorefinery, Nova Science Publishers, Inc., New York. 
[5] Eijsbouts, S. (1999). Life cycle of hydroprocessing catalysts and total catalyst management. Studies in Surface Science and Catalysis, 127, 21-36.

[6] Yoshimura, Y., and Furimsky, E. (1986). Oxidative regeneration of hydrotreating catalysts. Applied Catalysis, 23(1), 157-171.

[7] Furimsky, E., and Yoshimura, Y. (1987). Mechanism of oxidative regeneration of molybdate catalyst. Industrial \& Engineering Chemistry Research, 26(4), 657662.

[8] Yoshimura, Y., Sato, T., Shimada, H., Matsubayashi, N., Imamura, M., Nishijima, A., Yoshitomi, S., Kameoka, T., and Yanase, H. (1994). Oxidative Regeneration of Spent Molybdate and Tungstate Hydrotreating Catalysts. Energy \& Fuels, 8(2), 435-445.

[9] Massoth, F. E. (1967). Oxidation of Coked Silica-Alumina Catalyst. Industrial \& Engineering Chemistry Process Design and Development, 6(2), 200-207.

[10] Mickley, H. S., Nestor, J. W., and Gould, L. A. (1965). A kinetic study of the regeneration of a dehydrogenation catalyst. The Canadian Journal of Chemical Engineering, 43(2), 61-68.

[11] Leprince, P. (2001). Petroleum Refining. Vol. 3 Conversion Processes, Editions Technip.

[12] Vukovic, J., and Neuman, D. (2004). Ex-Situ Catalyst Treatments Reduce Refinery Emissions and Unit Downtime: Update on the Economic and Environmental Benefits of TRICAT's Ex-situ Regeneration and Pre-Activation Technologies. 5th EMEA Catalyst Technology ConferenceCannes, France.

[13] Dufresne, P., Valeri, F., and Abotteen, D. S. (1996). Continuous developments of catalyst off-site regenerationand presulfiding. Studies in Surface Science and Catalysis, 100, 253-262.

[14] Eijsbouts, S., Battiston, A. A., and van Leerdam, G. C. (2008). Life cycle of hydroprocessing catalysts and total catalyst management. Catalysis Today, 130(24), 361-373.

[15] Porocel (2017). Catalyst Rejuvenation. http://www.porocel.com/14rejuvenation catalyst_services/. (accessed on 5/1/2018)

[16] Stanislaus, A., Marafi, M., and Absi-Halabi, M. (1993). Studies on the rejuvenation of spent catalysts: effectiveness and selectivity in the removal of foulant metals from spent hydroprocessing catalysts in coked and decoked forms. Applied Catalysis A: General, 105(2), 195-203.

[17] Marafi, M. (2008). Spent Catalyst Waste Minimization and Utilization. http://thefutureenergy.org/wp-content/uploads/2018/02/2008Spent-CatalystWaste-Minimization-and-Utilization.pdf. (accessed on 5/1/2018)

[18] Marafi, M., and Stanislaus, A. (2008). Spent catalyst waste management: A review: Part I-Developments in hydroprocessing catalyst waste reduction and use. Resources, Conservation and Recycling, 52(6), 859-873.

[19] Furimsky, E. (1997). Activity of spent hydroprocessing catalysts and carbon supported catalysts for conversion of hydrogen sulphide. Applied Catalysis A: General, 156(2), 207-218.

[20] Trimm, D. L. (1989). Deactivation, Regeneration and Disposal of Hydroprocessing Catalysts. Studies in Surface Science and Catalysis, 53, 41-60.

[21] Furimsky, E. (1996). Spent refinery catalysts: Environment, safety and utilization. Catalysis Today, 30(4), 223-286. 
[22] Marafi, M., and Stanislaus, A. (2008). Spent hydroprocessing catalyst management: A review: Part II. Advances in metal recovery and safe disposal methods. Resources, Conservation and Recycling, 53(1), 1-26.

[23] Marafi, M., Stanislaus, A., and Furimsky, E. (2010). Chapter 11 - Metal Reclamation from Spent Hydroprocessing Catalysts. In: Handbook of Spent Hydroprocessing Catalysts, Elsevier, Amsterdam, pp: 269-315. DOI: 10.1016/B978-0-444-53556-6.00011-2

[24] Marafi, M., and Furimsky, E. (2017). Hydroprocessing Catalysts Containing Noble Metals: Deactivation, Regeneration, Metals Reclamation, and Environment and Safety. Energy \& Fuels, 31(6), 5711-5750.

Article copyright: (C) 2018 Changyan Yang, Jinlong Wu, Wei Wang, Bo Li, Bo Zhang and Yigang Ding. This is an open access article distributed under the terms of the Creative Commons Attribution 4.0 International License, which permits unrestricted use and distribution provided the original author and source are credited. 